\title{
Local Markets and Cultural Changes in Tanzania- Case of Moshi District, 1890s - 1950s
}

\author{
Editha Rambau
}

Mwenge Catholic University, Moshi, Tanzania

DOI:10.36348/SJHSS.2019.v04i09.001 | Received: 07.08.2019| Accepted: 22.08.2019 | Published: 20.09.2019

*Corresponding author: Editha Rambau

\section{Abstract}

This study examined the extent to which the presence of local markets in Moshi District Council, especially in Kibosho area, influenced the cultural change of the Chagga from the 1890s to 1950s. Specifically the study analyzed the presence of local markets as a complex sector of commercial activity among the Chagga. Local markets played an important role in social, economic, political and cultural change of African communities; which expressed the conceptual association of learning new practices outside the sphere of their families. Data for this study were collected through archival sources, oral interviews and secondary sources. It has drawn on Evolutionary Diffusion Theory to make sense of the extent at which the process of cultural diffusion was responsible for cultural change in Moshi Rural District as the Chagga came into contact with other cultures. The major finding of this study is that local markets had significant meaning in the history of the Chagga because they acted as a centre for cultural transformation through diffusion or adaptation.

Keyword: Local Markets, Cultural Change, Chagga, Transformation.

Copyright @ 2019: This is an open-access article distributed under the terms of the Creative Commons Attribution license which permits unrestricted use, distribution, and reproduction in any medium for non-commercial use (NonCommercial, or CC-BY-NC) provided the original author and source are credited.

\section{INTRODUCTION \\ Background to the Study}

In order to study markets one needs to examine not only the economic aspect of people in a particular area but also their culture. Harris P. and Morgan define culture as an important aspect of life which gives people a sense of unity, also it shows how people behave and what they should be doing at a particular period. Culture provides a learned, shared and interrelated set of symbols, codes and values that direct and justify human behavior [1].

There are many studies carried out about regional and local markets in Africa. Some of these studies, for example, The Study of Traditional Markets and its Organizations in West Africa by Holdder and Ukwi indicates that traditional markets among the Yoruba and Ibo people of West Africa existed as early as the long distance trade. These markets were mostly carried out by women at a specific day and served the whole community around the market places [2].

Helge Kjekshus [3], Isaria N. Kimambo ${ }^{[4]}$ and Sally Moore [5] noted that traditional markets existed in different parts of pre-colonial Tanganyika. At the beginning these markets and other forms of transaction ranged from barter trade, but later on they based on the exchange of goods for money. These markets served the broader purpose of trade and acted as centres for dissemination of information and social activities like offering sacrifices and settling of disputes especially those which occurred at the market places. Historians like Steven Fiereman and Isaria Kimambo have provided an important piece of information which shows the development of trade and markets during the $19^{\text {th }} \mathrm{C}$ in the Northern part of Tanganyika and how it had profound effects on the environment and people. They consider the development of caravan routes with the emergence of market centres in which the items such as food staff, ivory and later slaves were taken to the coastal areas in exchange for cloths, beads and guns. Such processes, contributed to the changes of the culture of the people who lived in the highlands of Tanganyika [6]. These historians also noted that conflicts and chaos among the societies in the Northern part of Tanganyika were due to the contact of Chagga with other societies like the Maasai, the Pare and the Swahili traders. This is to say, some Chiefs were aspired to move to the lowlands to form armed bands for raiding ivory and slaves as the main items of trade. Such situations transformed some of the social roles of the Chiefs especially from guarding their people to raid their own people who could become slaves [7].This situation changed the livelihood of the Chagga and 
created conflicts with traders of the Coastal areas as well as the Chiefs who were the main organizers of that trade.

The most important changes in the life of the Chagga occurred during the Germans rule. The Germans introduced new systems of life to the Chagga which included western education, Christian religion and new political system. During the German rule, markets as an economic and cultural institution continued to operate but under new principles and regulations. For instance, the Germans introduced money economy that replaced barter system which had a significant impact to the local markets. Likewise, the Germans introduced coffee production to the Chagga which acted as a common economic institution for unifying the Chagga as a single ethnic group which they formerly lacked. On one hand, the colonial production system did not only change the culture of the Chagga but also provided a political unity that was achieved through economic institutions. On the other hand, the Germans constructed infrastructures which simplified the process of interaction of the Chagga and the neighbouring societies. They also introduced new religion, that is Christianity, as well as western education which changed social-cultural practices of the Chagga [8].

From the 1920s some of the important changes in Northeastern Tanganyika were brought up by the British government who took over from the Germans' rule. The British administrators like the Germans, introduced cash economy, formal education as well as new cultural systems to the Chagga people. As noted by oral informants, the British built the first Parish in Kibosho and Kibosho Seminary in 1920s which became the major Christian seminary in the northern part of Tanganyika. This factor made most of the Chagga youth to be converted to Christianity.

Some scholars have noted that the 1920s marked the beginning of social, economic and political changes of the Chagga people. Isaria N. Kimambo, for instance, explained how the local people rejected some of the changes imposed by the British role in their political, economic and social aspects. He provided an example of the Mbiru protest among the Pare as a sign of critiquing and refusing the British rule in Kilimanjaro [9]. Therefore, in line with this argument, this study also investigated the changes brought by the colonialists such as new religion, education systems as well as the production of cash crops and how these changes contributed to the changes of the Chagga culture. It focuses on the existence of local markets in the Northern part of Tanganyika and the extent to which the establishment of the colonial administration changed their systems.

In most cases, it is difficult to separate traders, market places and social cultural aspects of the Chagga. These market institutions served as centres not only for exchange of goods and services but also for social and cultural interaction where people met and shared information and practices that developed their culture. Market, according to Richard Bagozz [10] and Sheldby Hunt [11], can be defined as an organisation of exchange relationship of not only goods but also services, ideas, knowledge and practices of the society. They also noted that the exchange of goods was not the only activity that was practiced in the markets but also they exchanged their ideas, values, customs and principles of their community [12]. In most cases the study about Local market have based on economic aspects; the issue of cultural aspects to some extent have been treated differently. But, we can study the culture of a particular group as a way of understanding the supply and consumer behaviour in a certain place. This is because culture involves all aspects of people's lives and the existence of local markets is the segment of economic-cultural aspect. It is important to note that the presence of local markets in a certain area is expressed not only the economic history of a given society but also cultural aspects of that society.

This study considered the presence of local markets in Moshi Rural District as a place for learning some of the cultural practices, customs and norms of their society as a result of internal integration or external adaptation. Markets are meeting points where people could get information from one person to another. Gossiping in market places was also considered as a way of conveying information as well as learning of cultural behaviour from elders and traders. Culture, as one among the social and economic aspect of people, developed as a result of the presence of local markets.

In real sense, culture goes through the process of changing, adaptation and diffusion as a result of contact with another culture. As noted by Burama Sagnia, culture can also be seen as a dynamic mechanism that must be adjusted and adopted to external and internal conditions of existence [13]. In relation to economic perspective, culture can be viewed as the sum total of shared values and practices that serve to direct consumer and supplier behaviour in a particular market place. This study covers the whole period of the colonial rule in Kilimanjaro where the system of markets and culture was also integrated into the European economy by the colonialists. Such situation led to the transformation of not only the economy of the Chagga - but also the social, political as well as their cultural aspects through cultural diffusion. This is to say, the spread of European ideas, technologies, politics and religions, especially Christianity to the Chagga was facilitated by the whole process of colonialism. For instance, the Europeans introduced cash economy in different parts of Kilimanjaro which was a new culture to the Chagga. This situation made the Chagga to engage more on cash economy and developed new economic culture, which was different from their subsistence production [14]. Scholars such as Isaria 
Kimambo, Sally Moore and others have analyzed the aspects of local markets in Tanganyika but have not sufficiently linked them with cultural changes and development of societies. This study was conceived to make a modest contribution to existing scholarship in order to highlight the relationship between local markets and cultural change, using Moshi Rural District as a case study.

\section{Statement of the Problem}

Previous studies conducted on the existence of local markets in Africa, particularly in Tanganyika, have generated a piece of useful information based on regional and local markets especially by analysing on the main participants of trade and the major items of trade in those markets [15]. Most of these studies examined on the caravan routes during the late $19^{\text {th }}$ Century and their impacts on the local communities. However, the development and organization of local markets and their impacts on the cultural aspects of the Chagga have not received adequate attention from historians. This study fills in this gap by exploring the relationship between the existence of local markets and its impacts on cultural change among the Chagga of Moshi Rural District focusing in Kibosho division from the 1890 s to 1950 s.

\section{OBJECTIVES OF THE STUDY General Objective}

The general objective of this study was to explore the ways in which the development of local markets changed the culture of the Chagga of Moshi Rural District, especially Kibosho Division, from the 1890 s to 1950 s.

\section{Specific Objectives}

The study has two specific objectives, namely to:

1. Examine the development and organization of the local markets among the Chagga of Moshi Rural District especially in Kibosho Division from the 1890 s to 1950 s.

2. To analyze the ways in which local markets influenced the cultural change of the Chagga of Moshi Rural District especially in Kibosho Division from the 1890 s to the 1950 s.

\section{Research Questions}

The study was guided by two questions:

1. How did local markets in Moshi Rural District especially in Kibosho area develop and operate from the 1890 s to 1950 s?

2. How did the development of local markets influence the culture of the Chagga in Moshi Rural District especially in Kibosho from the 1890s to 1950s?

\section{SIGNIFICANCE OF THE STUDY}

The study investigated the relationship between local markets and cultural change among the
Chagga of Moshi Rural District. The study adds a significant knowledge not only to economic aspects but also on the cultural aspects of the Chagga. It reveals the role of economy and culture in shaping African's life and provides better understanding on how culture can be incorporated in the study of economic aspects of certain communities by focusing on the contribution of local markets to the culture of the Chagga. Also the study focused on the ways in which the local markets were organized, the position of the local chiefs in organising those markets as well as the laws and principals that guided local markets are well discussed in this study. Furthermore, the study provides clues for further studies on the same or related topic can be developed to generate new knowledge.

\section{LITERATURE REVIEW}

Literature has established that local markets in Africa existed long before the colonization process. The pre-colonial African societies developed means of exchange between one society and another. The study conducted by B.W. Hodder and U.I. Ukwi shows that traditional markets among the Yoruba and Ibo people in West Africa existed even before the colonial era. The two authors have examined traditional markets that were conducted periodically and in most cases were carried out by women. However the organization and development of local markets in West Africa was interfered by the British administrators. During this period some of the traditional markets were closed while others were shifted in new places. On one hand, the power of local chiefs in organizing these markets was eroded. On the other hand, during the colonial era different infrastructures were constructed which facilitated the organization and development of local markets. Markets in West Africa acted as a place where people could gather for exchange of their commodities [16]. Their studies focused more on the economic aspects of local markets in developing Africa traditional societies. The aspect of cultural change in relation to the traditional markets was less emphased. Given that gap the study under discussion explored more on the relationship between local economy and their impacts on the cultural aspects of the Chagga of Kilimanjaro.

Scholars have also shown that the development of African local economies has contributed to the changes in political, social organisation, technological improvement as well as the cultural practices of the Africans. As noted by Jane Guyer in The Marginal Gains: Monetary Transactions in Atlantic Africa economic transactions of slaves, guns, currencies, sacrificial objects and food from precolonial time to the present expressed not only the economic aspects of the people, but also their cultural life. Guyer, referring to the study conducted by Bohannans among the Tiv people, noted that local exchange was carried out in a form of conveyances. Trade was carried out in form of barter system. For example, items like cloth were exchanged with brass rods or brass with fire arms or cattle with bride wealth 
and so on. The way people involved in transaction process develops their cultural aspect and norms through getting new things. Her study helps to show how economic exchange within African regions was integrated into European history which changed the monetary dynamics of Africa economies as well as their cultural aspects [17].

The works of Dalton George provides a detailed historical descriptions about the ways in which colonialists integrated the life of Africans economically, culturally, politically and socially into their Western spheres of life. Despite the destructive nature of the colonial impacts in forcing socio-economic changes that was not meaningful to Africans, the local markets in Africa continued to exist though with some changes [18]. For instance, the introduction of new administration system as well as new places for trade changed the organisation of local markets in Kilimanjaro.

The introduction of the capitalist economy in Africa brought its own forms of commodity exchange though the local markets continued to operate. Colonialists did not intend to make African wealth off materially; therefore, they destroyed some of the cultural and social organizations of which the indigenous economy was an inextricable part. Moreover, the power of traditional chiefs who had been the final market authority was reduced and redefined in the colonial regime. This claim is most evident in the works of Susan Geiger [19], Kathleen Stahl [20], Sally Moore [21], Helge Kjekshus [22] and Isaria Kimambo [23], These scholars provided an important piece of information concerned with the development of Chagga economy in relation to colonial economy which facilitated the transformation of their economic, social, political and cultural aspects. For instance, the introduction of colonial economy in Moshi Rural District changed the subsistence production system of the Chagga by involving them in the cash crop production. Colonial economy also forced the Chagga to adopt new system of leadership like the use of direct rule which was not part of their politics.

In fact, Mount Kilimanjaro influenced the geographical condition of the Chagga who lived in a strategic economic position by providing moderate climatic condition which allows people to engage in different economic activities. For example, livestock keeping, farming, trade etc; People of the mountain traded not only with each other but also with neighbouring communities. For instance, the study which was carried out by Michael Sheridan in North Pare about The Culture and Agriculture in Pre-colonial Societies noted that the existence of regional markets gave the Pare people more opportunities to interact with their neighbouring societies. Regional markets also served as a powerful incentive and opportunity to convert surplus into wealth through trading centres.
Sheridan also noted that regional markets enabled people to overcome the problem of unreliable rainfall by trading with another society from different areas. The regional markets in pre-colonial African societies were dominated by men who exchanged livestock, food items, iron equipments and crafts with the people of the lowland [24].

The development of regional markets which involved long distance trade to a great extent contributed to the rise of local markets in Kilimanjaro. The regional markets developed earlier than the local markets and its development based on interaction between two or more communities over a long distance. As pointed out by various scholars like Helge Kjekshus [25], Juhan Koponen [26], Isaria Kimambo [27] and Edward Kileo [28] the Chagga had participated in a wider sphere of economic exchange with the neighbouring communities. The above scholars also noted that in most cases, regional and local exchanges were always conducted without markets but only few communities like those of the north-eastern mountains, that is, the Chagga and Pare had institutionalized markets for the exchange of their surplus food and other items on a barter basis. Moreover, goods that were traded in the regional markets were also used as items of trade in the local markets. Kimambo, for instance, provides an example of Kahe and Pare markets which provided cooking pots which were used as items of trade in the Chagga local markets.

At the beginning of the $19^{\text {th }}$ Century, the system of exchange among the Chagga was highly structured and the exchange was for the use value. Other factors for the development of markets were the development of agriculture and animal keeping, which in turn were used as items of trade in the markets [29] Juhan Koponen provided influential information about local markets in Kilimanjaro especially those which were organised by women based on the exchange of food stuff with other commodities from neighbouring societies. He also indicated that there were several places in which markets were held especially after every three to four days [30].The issue of local markets and cultural change is not well discussed in his book therefore, this study develop more analysis on the impact of local markets and cultural change of the Chagga.

This current study examined the development of local markets and cultural change from the 1890s to 1950 s, the period when most of the economic, political and social-cultural changes took place in Kilimanjaro. Helge Kjekshus, Sally Moore, Gerger and Isaria N. Kimambo developed a line of argument that links the penetration of the imperialist powers and the capitalist administration to the transformation of ways of life of the Chagga of Kilimanjaro. Kimambo, for instance, noted that the penetration of colonial economy integrated the Pare subsistence economy into colonial 
economy which brought important changes in the social relation of production of the Pare. For instance, the colonialists put more emphasis on production of coffee as well as sisal crops and less emphasis on the production of subsistence crops which were the major items of trade in their local markets. This is to say, the system of local markets continued during the colonial era but with scarcity of items of trade in the markets. This shows that in most cases the introduction of cash economy hindered the production of subsistence economy; hence the number of items in the local markets was scarce. In most cases the changes which took place in Kilimanjaro were brought up by the colonialists who introduced not only the new economic system, but also new social aspects to the natives.

As it was noted by Amy Stambach in his study about Seeded in the Market economy: Schooling and Social Transformations on Mountain Kilimanjaro, during the $19^{\text {th }}$ Century the idea of Chagga about land and livestock changed with the modern social development which was introduced by the capitalists. For instance, Stambach referred to "School" as an institution created by the Europeans not only for broadening the value of the people around the Mountain but also for transforming the social understanding of the society [31]. These changes made the local people to react against the extreme pressure placed on them by the colonialists. That is to say that the natives were generally embraced with colonial economic, political and social systems which often worked against the Chagga interests. It can be noted that regional and local markets influenced by the introduction of cash exchange which replaced the barter system although colonial authority to some extent interfered the system of local markets especially the rules and laws that were implemented by the colonial rule. Helge Kjekshus provided a useful piece of information which shows that colonial administrators interfered more direct the traditional market systems of the Chagga. It can be noted that some of the local markets were closed especially those of interior areas such as Uru and Marangu areas [32]. This situation made the Chagga to react against the laws that undermined their exchange systems especially reduction of the number of market places. The colonial authority also introduced new market centres, for example, the market centre next to District Office at Old Moshi which later became one of the big markets in Kilimanjaro. But these new markets were located very far from the native residence, therefore; it was difficult for people to attend regularly [33]. These scholars provided information on the existences of local markets and how the colonial system interfered these markets but the how these markets changed the cultural aspects of the Africans were not well articulated.

\section{THEORETICAL FRAMEWORK}

This study was guided by Evolutionary Diffusion Theory formally developed by the anthropologist Ralph Linton who provided a theoretical foundation for analyzing cultural change. This theory is based on the sociological concept of diffusion. Linton believed that the process of cultural change can be categorized into four stages. The first stage is the presentation of a new cultural element to the society. At this stage society acquired new elements of culture as a result of contact with other societies [34]. For the case of local markets among the Chagga this stage presented a new cultural dimension as a result of contact with other societies. The second stage, according to Linton, is acceptance and rejection of cultural elements. At this stage, society decided to accept or to reject a particular element of culture. As far as the Chagga were concerned, not all elements of new culture were accepted to their societies. For instance, the issue of traditional religion was preserved despite the new element of Western Christian religion [34].

It can be noted that customs and traditions that guided the organization and protection of local markets were protected although some elements of culture like the introduction of new items of trade, new food products were accepted [35]. The third stage, according to Linton, is the adjustments made between the new cultural elements and the receiving society. In this case, the society can adjust according to the new culture that was introduced in their areas. For instance, the Chagga after accepting the new ways of making and using iron tools from the Pare and the Maasai societies they made it as part of their society.

The fourth stage, according to Linton, is the elimination of older cultural element which the society had before interaction. In this stage, the new culture overthrew the element of older culture [36]. This was possible with the existence of local markets in Kilimanjaro areas. That is to say, the existence of new elements of culture like the introduction of money economy outweighed the barter system which existed before. It can be noted that all human being can acquire new culture from other societies. Evolutionary Diffusion Theory implies that culture can be influenced by other societies through interactions. This interaction facilitates the spread of cultural elements such as ideas, styles, food, religions, and technologies from one culture to another. New items appear simultaneously and independently in different places when certain items are diffused to respective communities. Evolutionary Diffusion Theory also puts much emphasis on cultural borrowing as a result of contact of two cultures and borrowing from each other. That is to say borrowing is not symmetrical; it depends on the nature and the duration of the contact and for this case, it depends on the nature of interaction. The process of cultural change is facilitated by internal and external processes as it involves innovation, borrowing and cultural diffusion Cultural diffusion is responsible for the greatest amount of cultural change that occurred in any society. The process of cultural diffusion is 
selective in nature especially when two cultures come into contact; but not necessary that every cultural item is changed, some of the cultural items can be diffused to another.

\section{SCOPE OF THE STUDY}

The study was carried out among the Chagga of Moshi Rural District, and Kibosho area served as a case study. Kibosho area was selected because it has passed through a different periods of social-cultural, political and economic changes that were tied to the development of trade and local markets. From 1890s this area experienced internal and external conflicts with the whites and also with the neighboring communities. These conflicts marked the historical changes in the system of economy, political and social aspects. During the colonial era, Kibosho area was one of the places in Tanganyika with good political influences therefore they managed to negotiate the colonial domination. Moreover, Kibosho area was the best place for this study because it has a good number of local markets some of which existed before, during and after the colonial period. It was thus possible to retrieve stories and memories on colonial local markets which are central to this study. The temporal frame of the study which starts in the 1890s and ends in the 1950 s was purposely selected in order to capture the interplay between markets and culture among the Chagga during the colonial period. However, discussion of culture and markets starts before the 1890s in order to provide enough background information on precolonial Chagga society as a basis for making sense of the colonial situation.

\section{RESEARCH METHODOLOGIES}

This study has collected qualitative data in order to understand the extent to which local markets in Kibosho area influenced the transformation of the Chagga culture. Three types of data have been used in this study: archival records, oral recollections, and secondary information. The researcher started by library sources especially from the University of Dar es Salaam Library were the secondary information was obtained especially from books, journals and reports. These secondary sources provided information on the markets especially regional markets in Africa and Tanganyika in particular. Also the information about the Chagga customs, beliefs and traditions was also obtained from this library. This information was very important especially on the background of the study and literature review and helped to identify the knowledge gap.

This study also used primary data which were obtained mainly from the Tanganyika National Archives (T.N.A). In T.N.A researcher collected information from correspondence about Colonial Moshi District records, letters, secretarial files, District Reports and different Records. From District book, information concerning with the History of the Chagga especially their economic activities, their customs, beliefs, tradition and social cultural practices were obtained. Various original documents such as letters that were written by the local chief to the District Commissioner to request for new markets, letter from the local authorities to "Mangi Mkuu to request him to prohibit Kibosho women from selling their bananas in Moshi town. Also letters shows boundary conflicts within Kibosho area especially in Kindi and Kombo ward and how the local people were dissatisfied with the boundary division and re-division were also found in T.N.A. Letters on furrow constructions in Kibosho area and other important information were also obtained from letters.

Different reports also were obtained from colonial files especially on how local markets were established and the way of collecting tax from the market places in Tanganyika. Also, information about colonial administrative system, their economic systems, their politics as well as the cultural aspects were also collected from archival source. At T.N.A there was also a reasonable deposit of materials concerning local markets in Moshi District and the ways which colonial authority changed the operation of these markets.It can be noted that this study collected information from papers from the sociologists and anthropologists especially Henry Fosbrooke, provided information on the social setting of the Chagga and their neighbours, especially the early exploration of Kilimanjaro. Some of the papers showed the pre colonial history of the Chagga, their languages and their cultural background. This knowledge was very important to this study because it helped to add information on the chapter two of the study.

However, archival source did not provide enough information to fill in the gaps of secondary data. Therefore, oral interviews were also conducted to fill the gaps left uncovered by written sources. The guide questions for interviews were used to ensure coherence to enable the author to get information from the indigenous people of Kibosho area. By considering the historical time being investigated the key informants were consulted including the Ward and Village elders, of previous years and those who were the tax collector at those markets had information about the existence of local markets in their areas. Also clan leaders they provided enough information on the cultural aspects of the Chagga and how their culture changed overtime. The researcher interviewed also some of the former workers who were employed by the British colonial authorities as cooks, house workers and local rulers provided their perspectives concerning with the study. In fact, with interview, the author was able to elicit some important information about markets, its organization and their influences on the cultural change among the Chagga who had either witnessed or heard information from others but their knowledge was not recorded in written form. 
Field work was conducted in Moshi Rural District especially in Kibosho Division including the Kindi, Okaoni, Kibosho Magharibi, Kibosho Mashariki and Kirima Wards. This area was purposively selected because, it has good number of local markets which was has long history compared to other areas. Also selected area has strong political influences especially during the colonial era which enable them to control different local markets.After collecting data, the information from different sources was properly analysed. The researcher first, reviewed and evaluated the raw data as it was collected from different sources to ensure its validity and reliability. The information was then interpreted qualitatively according to themes and depending on the research questions and objectives. The interview results were analysed using descriptive methods based on the objectives of the study. Moreover, the researcher integrated and collaborate data from archival, library and oral interviews to come up with reliable information about the study. Therefore, a combination of descriptive and analytical statements was very important especially to overcome the contradictions from the information provided from different sources. Moreover, the use of oral sources helped to answer many questions that were not answered by other sources.

\section{FINDINGS OF THE STUDY}

The study examined that the concept of culture as a system of beliefs, values, customs, and traditions was practiced within the society and shared by a group of people in a certain society. It determines the social, political and economic aspects of a given society. The study also examined the evolution of local markets among the Chagga on the influence of cultural aspects of the Chagga in Kilimanjaro. From the findings it shows that markets were the points of interactions among the Chagga and between the Chagga and neighboring communities. As noted by Isaria Kimambo in his Oral Collections, that the Chagga had interaction with the Wagweno, Wakahe and Wamasai who left their homes and brought with them quantities of maize cobs, bananas, iron tools and some cattle in Kilimanjaro for trade activities[37]. As people interact through markets they shared many things such as language, customs, traditions, arts, habits, knowledge, and skills.

The study also examined that the presence of regional markets in Moshi Rural District made the Chagga to learn some new cultural aspects from the Pare, Maasai, Kamba as well as the Kikuyu who had contact with them even before the colonial era. For The presence of Laitoktok market at the border of Kilimanjaro and Kenya exemplified the existence of cultural contact between the Kamba and Kikuyu of Kenya and the Chagga of Kilimanjaro. The Chagga adopted skills of making baskets from the Kamba. They also adopted different ways of conducting their ritual aspects, like carrying out sacrifices as a way of respecting their ancestors, from the Kikuyu.
In addition, the Chagga acquired the skills of producing pottery and baskets from the Kamba and the Pare people through market interactions [38]. The culture of marking pots spread in almost all areas of Kilimanjaro but mostly in the Southern parts of Rombo and Narumu areas in Kibosho. Finally, the Chagga learned the culture of iron making from the Pare. Other communities learned new cultural values from the Chagga also. The Pare, for instance, acquired the knowledge of making local brew, mbege, from the Chagga. It can be noted that the interaction between the Chagga and the neighboring societies made them to change their culture through acquisition of new products, ideas, values as well as new technologies.

Furthermore, the study examined the development of regional trading patterns in the Northern part of Tanganyika. These markets accompanied with the expansion of trade and Swahili culture from the mid of the $19^{\text {th }} \mathrm{C}$ which to some extent facilitated the development of the Chagga culture. The history of political, social as well as the economic development of the Chagga was connected to the functioning of local markets which enhanced cultural interactions of the Chagga with other societies.

It can be noted that colonial rule, Christianity, coffee production and western education also had contributed to the changes of Chagga customs and traditions. As exemplified by Sally Falk Moore that, the introduction of Christianity in Kilimanjaro by the European missionaries changed some of the social cultural practices of the Chagga such as the Chagga traditional religion, marriage systems as well as the ways of imparting knowledge to youth. It discouraged most of the socio-cultural practices of the Chagga, such as offering sacrifices to ancestors, polygamies and many others [39]. Although, some Chagga adopted Christianity they continued to maintain some of their traditions together with the mainstream Christianity. This was carried out by the members of the family although under maximum secret.

The introduction of coffee production made the Chagga to improve their standard of life as they earn income from coffee. This was also exemplified by the study carried out by Fabian Massawe that the increase in coffee production from 1930s made the value of land to increase as many people owned large tracts of land for coffee production [40]. Coffee production also interfered the production of local products that were used for exchange in the local markets. In most cases women who were the main participants of local markets were busy with coffee production during this period. Therefore the number of market attendants to some extent was minimal.

Furthermore, the study assessed the contribution of the Chagga Chiefs in organizing and 
developing these markets in Moshi Rural District. In most cases local Chiefs were responsible to request for new areas for establishing new markets to the District Commissioner after they had discussed with the natives of a particular area [41]. Chiefs also had obligation of ensure peace and security in their areas as well as in the market places. In case of conflicts or fighting in the market places chiefs were also informed and discuss the case as well as imposing penalty to the one with offense.

Therefore, from this study it can be noted that the highly organized market system among the Chagga permitted the exchange of local foodstuffs and served as a means of social interaction within their localities and with the neighboring societies. This situation made them to change their culture through adopting new ideas, knowledge and skills from other societies.

Finally, this study on Local market and its impacts on the cultural transformation of the Chagga of Kibosho area during the colonial rule examined the relationship between culture and economic aspects of the African societies. The interaction in terms of language, behavior, ideas and practices that were common at local markets were either modified or adopted or borrowed by another society through contacts. This is to say, the development of local markets in Kilimanjaro made the Chagga to acquire some of the cultural values like ideas, goods, concepts, technologies etc through contacts with their neighboring communities.

\section{SUMMARY AND CONCLUSION}

From the study it can be noted that culture is at the centre of people's life and it was/is expected that it has impacts on the organisation and development of the local markets. The role of the market underlies the cultural value, norms and practices of a given society but sometimes culture can affect the kind of roles and choices of themes depicted in the markets noted that the absence of certain cultural values and practices in a given society made that society to be dormant. It can be noted that culture is everything that society is doing; even the aspect of market economy could not come into existence without the influence of culture. Once market economy does not exist in the given society; it seems to discourage some of the ways of life [42]. For instance, the issue of social interaction among members of a certain community and another, the economic aspects of a given society could be dormant in the absence of markets.

However, in most cases the economists understand the concept of markets, but rarely treat it as part of culture. The relationship between markets and culture is an interesting area where this study managed to elicit the information which shows how local markets changed the culture of a certain society. There have been several studies that highlight the positive relationship between market systems and cultural attitudes, beliefs and orientations of certain societies since culture partly determines the market procedures.
Since culture plays a significant role in determining who can legitimately engage in those markets and what constitutes an acceptable exchange items, the traditional market employs cultural laws in determining what is supposed to be brought in the markets and the type of people who were allowed to go in those markets.

This study did not exhaust everything concerned with the history of Chagga. The study lays the foundation for further studies on related themes, specifically on the impacts of local conflict in establishment of local markets. Other areas of inquiry can be the influence of local markets on the economic development of the Chagga, the gendered nature of local markets, and the relationship between local markets and sexually transmitted infections.

\section{REFERENCES}

1. Harris, P. R., Moran, R. T., \& Andrews, J. (1991). Managing cultural differences (Vol. 3). Houston, TX: Gulf Publishing Company.

2. Hodder, B. W., \& Ukwu, U. I. (1969). Markets in West Africa. Studies of markets and trade among the Yoruba and Ibo. Markets in West Africa. Studies of markets and trade among the Yoruba and Ibo.

3. Hodgson, D. L. (1997). Ecology Control and Economic Development in East African History: The Case of Tanganyika, 1850-1950, Second Impression.

4. Kimambo, I. N. (1991). Penetration \& protest in Tanzania: the impact of the world economy on the Pare, 1860-1960. London: James Currey.

5. Facts, S. (1986). Fabrications:" Customary" Law on Kilimanjaro, 1880-1980. Cambridge: Cam.

6. Feierman, S. (1974). The Shambaa kingdom: A history. [Madison]: University of Wisconsin Press.

7. Caldeira, A. O., \& Leggett, A. J. (1983). Erratum Ibid. Ann Phys (NY), 153, 445.

8. Lema, A. A. (1999). Chaga Religion and Missionary Christianity on Kilimanjaro: The Initial Phase, 1893-1916. East African Expressions of Christianity, 39-62.

9. Kimambo, I. N., \& Temu, A. J. (1969). A history of Tanzania. Published for the Historical Association of Tanzania [by] East African Pub. House.

10. Bagozzi, P. R. (1975) "Markets as an Exchange", in Journal of Marketing, 32-39.

11. Hunt, S. D. (1971). The morphology of theory and the general theory of marketing. Journal of marketing, 35(2), 65-68.

12. Ibid. p.66.

13. Sagnia, B. (1997) 'Workshop on Culture, Gender and Development in Eastern and Southern Africa English- Speaker Countries, Addis Ababa Ethiopia 8-11 April, p.7.

14. Ibid.

15. Kimambo, I. N., \& Temu, A. J. (1969). A history of Tanzania. Published for the Historical Association of Tanzania [by] East African Pub. House. 
16. Wingfield, C. (2009). Patterns of connection: Ostrich eggshell beads, the environment and sociality in the Kalahari. Saarbrücken: VDM Publishing.

17. Guyer, J. I. (2004). Marginal gains: monetary transactions in Atlantic Africa(Vol. 1997). University of Chicago ress..

18. Dalton, G. (1962). Traditional production in primitive African economies. The Quarterly Journal of Economics, 76(3), 360-378.

19. S. Geiger, "The Political Focus in Kilimanjaro" (Ph.DThesis, University of Dar es Salaam,1972), pp. 155-160.

20. Stahl, K. M. (1964). History of the Chagga people of Kilimanjaro (Vol. 2). Mouton.

21. Facts, S. (1986). Fabrications:" Customary" Law on Kilimanjaro, 1880-1980. Cambridge: Cam.

22. Kjekshus, H. (1996). Ecology control and economic development in east African history: The case of Tanganyika. Currey.

23. Kimambo, I. N. (1991). Penetration \& protest in Tanzania: the impact of the world economy on the Pare, 1860-1960. London: James Currey.

24. Sheridan, M. A. (1988). Lipid dynamics in fish: aspects of absorption, transportation, deposition and mobilization. Comparative Biochemistry and Physiology Part B: Comparative Biochemistry, 90(4), 679-690.

25. Kjekshus, J., Apetrei, E., Barrios, V., Böhm, M., Cleland, J. G., Cornel, J. H., ... \& Gullestad, L. (2007). Rosuvastatin in older patients with systolic heart failure. New England Journal of Medicine, 357(22), 2248-2261.

26. Koponen, op,cit.,p.103.

27. Kimambo, I. N. (1969). A political history of the Pare of Tanzania, c1500-1900 (Vol. 3). East African Pub. House..

28. E. S. Kileo, "The Political Development and Conflicts in the History of Chagga People from 1928-1963: A Case Study of Chagga Council from
1928-1963" (M.A- Dissertation, University of Dar es Salaam, 2005), p.34.

29. Ibid. p.24.

30. Koponen, op.cit., p.134.

31. Stambach, A. (1996). "Seeded" in the Market Economy: Schooling and Social Transformations on Mount Kilimanjaro. Anthropology \& education quarterly, 27(4), 545-567.

32. Kjekshus., op.cit., p.115.

33. Ibid. p.115.

34. R. J. Liston, "The Tree of Culture" (The University of Michigan Press, 1955), pp.41-42.

35. Moore, op.cit., (1986).p. 334.

36. Interview with R. Mushi, Kitandu Village, Okaoni ward in 22/2/2014.

37. Ralph, op.cit., pp.44-45

38. Kimambo, I. N. (1969). A political history of the Pare of Tanzania, c1500-1900(Vol. 3). East African Pub. House.

39. Ibid. Kimambo, Collection p.102.

40. Moore, S. F. (1986). Social facts and fabrications" Customary" law on Kilimanjaro, 1880-1980. CUP Archive.

41. F. Massawe, "The Penetration of Capital and the Coffee Economy in Kilimanjaro and Peasant Responses Seeking Alternative Means to Earn Cash Income: The Case of Kifuuni Village in Kibosho Division", (M.A Dissertation, at the University of Dar es Salaam, 1988), p.67.

42. T NA, 78 Letter dated $18^{\text {th }}$ June 1952 from Mangi of Mkuu to Mangi of Kibosho to prohibit women from selling their banana in Moshi town. ... Instead he wanted the Kibosho women to preserve their plantain by dried them for future use. Also Mr. Kuria Kagunda of Kikuyu tribe in Kenya wrote a letter dated $6^{\text {th }}$ June 1952 to District Commissioner to request for permission to buy banana plantain from the Chagga people, but District Commissioner refused to allow $\mathrm{Mr}$. Kagunda to do so. 